\title{
ESCRITAS DE SI EM NARRATIVAS AUDIOVISUAIS: O DOCUMENTÁRIO MUITO ALÉM DA VISÃO ${ }^{1}$
}

\author{
Marcela Ferreira Lopes ${ }^{2}$ \\ Márdel Pereira dos Santos ${ }^{3}$
}

\begin{abstract}
Resumo: Neste trabalho, as narrativas audiovisuais, notadamente o documentário, serão tratadas como obras que agenciam a escrita de si sob outras perspectivas, na medida em que a escrita autoral, confessional presente em diários e cartas é substituída pela presença física de um sujeito posicionado ante a objetiva para colocar em cena suas memórias ao mesmo tempo em que explora aspectos inerentes de uma subjetividade individual e coletiva, responsáveis pela constituição do sujeito que fala. Para tanto, o curta-metragem Muito além da visão (Carvalho; Santos; Soares, 2016) será acionado para revelar como Jailson reconstrói suas experiências ao relatar episódios marcantes de sua trajetória de homem que se tornara cego no começo da adolescência e como se dá a sua inserção no mercado de trabalho.
\end{abstract}

Palavras-chave: Escritas de si. Muito além da visão. Narrativas audiovisuais.

\begin{abstract}
In this paper, audiovisual narratives, particularly documentaries, will approached as works which modulate the self-writing from other perspectives inasmuch as authorial and confessional writing found in journals and letters is replaced by the physical presence of a subject placed before an individual and collective subjective point of view, through which the speaking subject is constituted. In this sense, the documentary, Muito além da visão (Carvalho; Santos; Soares, 2016), will be examined to enlighten how Jailson reconstructs his experiences as he relates meaningful accounts concerning his trajectory as a subject who turns blind on the onset of his adolescence and how his insertion in the business world occurs.
\end{abstract}

Keywords: Self-writing. Muito além da visão. Audivisual narratives.

\footnotetext{
${ }^{1}$ Documentário produzido no âmbito do Projeto Minha Casa Nossas Vidas através da parceria CaixaUFBA, disponível em https://labor.ufba.br/midiateca/midiateca/curta-metragem-muito-alem-da-visao.

2 Mestranda do Programa de Pós-Graduação em Crítica Cultural (UNEB). Email: mfl.marcela@gmail.com

3 Mestrando do Programa de Pós-Graduação em Desenvolvimento e Gestão Social (UFBA). Email: mardelpettos@gmail.com
} 
Se o documentário Muito além da visão fosse um texto escrito seria semelhante a uma carta pessoal: destina-se a outra(s) pessoa(s) ao mesmo tempo em que permite "o exercício de escrita pessoal" (FOUCAULT, 2004, p. 153), uma vez que seu principal personagem - Jailson, escreve/fala de si mesmo ao reativar aspectos singulares de suas experiências cotidianas além de interagir com outras pessoas (o que nos gêneros escritos seriam as várias leituras feitas de autores e textos diversos, nas narrativas audiovisuais e demais modalidades orais são a escuta) como forma de constituir uma unidade, um ethos, pois "sempre se precisa da ajuda de outro na elaboração da alma sobre si mesma" (SÊNECA apud FOUCAULT, 2004, p. 154). A perda da visão aos treze anos de idade é o vetor utilizado por Jailson para acionar suas memórias, pois, é a partir desse episódio que ele se vê obrigado a reinventar-se para continuar existindo numa sociedade de videntes, especialmente para não ser excluído do mercado de trabalho (isso, claro, pensando na invisibilidade a que a sociedade condena as pessoas que não atendem a um determinado padrão). Embora não seja, em princípio, uma admoestação aos seus interlocutores, o documentário "desempenha o papel de um princípio de reativação: reativação de todas as razões que possibilitam superar" (FOUCAULT, 2004, p. 154) situações adversas passíveis de enfraquecer aquele que as enfrenta, ou seja, Jailson usa o vídeo para mostrar, ao mesmo tempo em que reflete sobre suas ações, como ele superou as adversidades enfrentadas diariamente em seu processo de reinvenção de si enquanto homem cego para viabilizar tanto a interação com outras pessoas quanto sua inserção no mercado de trabalho. Além disso, é também uma "retribuição de conselho" uma vez que ao contar suas experiências ele o faz com base em seu aprendizado desenvolvido no contato com outras pessoas e no crescimento pessoal. Tanto é assim, que a trajetória de Jailson começa justamente quando sua mãe o matricula no Instituto de Cegos da Bahia já nos primeiros momentos da cegueira para evitar o isolamento dele. No entanto, conforme assinala Foucault,

a correspondência é mais do que um adestramento de si mesmo pela escrita, através dos conselhos e advertências dados ao outro: constitui também uma certa maneira de se manifestar para si mesmo e para os outros. A carta torna o escritor "presente" para aquele a quem ele a envia. E presente não simplesmente pelas informações que ele lhe dá sobre sua vida, suas atividades, seus sucessos e 
fracassos, suas venturas e desventuras; presente com uma espécie de presença imediata e quase física (FOUCAULT, 2004, p. 155-156).

Ciente de que poderia contar sua história para mais pessoas (manifestar-se, segundo Foucault), Jailson encontra no projeto Minha Casa Nossas Vidas a maneira certa para levar suas experiências adiante. Iniciado em janeiro de 2014, o Projeto realiza ações necessárias ao desenvolvimento sustentável da comunidade do Residencial Bosque das Bromélias (Salvador-BA), através da parceira UFBA-CAIXA. O empreendimento é visto como um território bastante complexo: localiza-se em área afastada do centro; não possui infraestrutura básica, a exemplo de escolas, postos de saúde, comércio, transporte etc.; sua população de cerca de 7.200 pessoas é constituída de 2.400 famílias oriundas de espaços e movimentos sociais diversos, como os Sem-Teto, cujos laços socioafetivos preexistentes foram desfeitos na mudança para o Bromélias, uma vez que nem todos foram morar no mesmo lugar; a maioria dos habitantes possui cerca de 30 anos de idade e necessita de emprego e qualificação profissional. De acordo com o site oficial ${ }^{4}$, o projeto busca reverter essa realidade a partir do cumprimento de seis metas norteadoras de todas as ações, a saber: "Contextualização do cenário e diagnóstico; Formação cidadã e qualificação profissional; Comunicação e cultura; Requalificação das áreas verdes; Saúde e qualidade de vida; Governança territorial”. Para tanto, diversas outras parcerias têm sido realizadas, a exemplo da estabelecida com o sistema $S$ (Sebrae, Senai, Sesc e Senac) que tem promovido cursos profissionalizantes como o de panificação.

Apesar do quadro geral, o Residencial Bosque das Bromélias não deve ser identificado apenas pelo que lhe falta, pois, a comunidade que surgiu a partir da fragmentação de histórias, relações afetivas, sonhos e projetos de futuro os mais variados, possui na diversidade uma de suas características mais marcantes. Jailson é um que se destaca entre os vizinhos. Responsável por incentivar a população a lutar por direitos e buscar melhorias, passou a ser reconhecido como uma liderança importante do território por falar em nome das pessoas com deficiência, ou, como ele destaca no documentário, "a voz do que é de direito nosso". Partiu dele a ideia de fazer o filme Muito além da visão, gesto que pode ser interpretado como uma

\footnotetext{
${ }^{4}$ Informações mais detalhadas sobre o projeto e as ações desenvolvidas podem ser encontradas no site <https://labor.ufba.br/colabore>
} 
prova da legitimidade recebida pela qualidade de sua liderança e história de vida. Em síntese, o vídeo é centrado na figura de Jailson interagindo em dois dos principais espaços de circulação dele: o Instituto de Cegos da Bahia e o Residencial Bosque das Bromélias. Em pouco mais de seis minutos, ele narra episódios importantes de sua vida desde que ficou cego aos treze anos de idade até a chegada ao empreendimento onde mora atualmente com esposa e filhos, além de expor sua rotina atual e fazer projeções para o futuro. No vídeo, a história dele é cotejada com a de Evilázio, amigo que conhecera no Instituto e com quem aprendeu a consertar micro-ondas e estabeleceu parcerias.

Conforme afirmamos anteriormente, Muito além da visão assemelha-se a uma carta haja vista ser a forma escolhida por Jailson para examinar a si mesmo num exercício pessoal de "subjetivação do discurso" ao mesmo tempo em que se coloca à disposição para escrutínio de seus destinatários (FOUCAULT, 2004, p. 156). Mas o vídeo tem suas peculiaridades. Uma delas está diretamente relacionada às condições de produção da obra. Segundo Eni Orlandi (2003), as condições de produção são um princípio teórico da análise do discurso responsável por tratar o texto como objeto inacabado e intervalar uma vez que, mesmo distintas, produção e recepção convergem para o espaço discursivo através da interação estabelecida entre os interlocutores e mediada por fatores como a situação e o contexto histórico em que a obra foi produzida. Destaca a autora,

[...] pensando-se o texto como unidade complexa de significação consideradas suas condições de realização - e procurando caracterizá-lo em termos de processo de interação, podemos ainda observar que o texto não é uma unidade completa, pois sua natureza é intervalar (ORLANDI, 2003, p. 180, grifo da autora).

Há no documentário, pelo menos, dois intervalos distintos responsáveis pela feitura da obra. O primeiro é o que se estabelece entre Jailson e a equipe de filmagem. É ele quem decide falar de si, contar sua história de vida. Ele também orienta quanto ao que deve ser gravado: Instituto; área externa do condomínio; ele andando na rua e interagindo com os vizinhos; fazendo reparos elétricos em casa e participando da oficina de conserto de micro-ondas com outros deficientes visuais orientados por Evilázio. Mas, apesar da equipe técnica funcionar como o escriba que escreve a carta ditada pelo autor, há uma autonomia a ser considerada, pois o modo como as ideias de Jailson são transformadas em imagens também depende de 
escolhas feitas pela equipe, independente da vontade de Jailson. Ou, como afirma o personagem Antônio Biá (José Dumont) do filme Narradores de Javé (Eliane Caffé, 2003): "Uma coisa é o fato acontecido. Outra coisa é o fato escrito. O acontecido tem que ser melhorado no escrito de forma melhor para que o povo creia no acontecido". No caso do documentário, a narração fica a cargo do depoente; no entanto, cabe à equipe técnica decidir, por exemplo, sobre o que vai ser mantido no produto final; qual a ordem de entrada e duração de cada imagem; bem como a melhor forma de intercalar as falas de Jailson e Evilázio. O início do vídeo fornece alguns elementos básicos para compreender a natureza de tal afirmação. Não há dúvidas quanto à identidade de seu protagonista. Porém, a voz em off que ouvimos no começo enquanto os créditos iniciais surgem sobre o fundo preto é a de Evilázio ensinando aos alunos da oficina sobre conserto de micro-ondas como reconhecer as partes internas do aparelho. Terminado os créditos, vemos Jailson tomando a palavra. Aqueles que o conhecem sabem de imediato que não é sua voz que aparece anteriormente. Os demais estão às cegas. Uma estratégia da produção para colocar o espectador momentaneamente no lugar do outro. O resultado desse primeiro intervalo pode ser apreciado em toda a extensão do filme, que compila em seis minutos e quarenta segundos o conteúdo obtido em horas de filmagem.

O segundo intervalo é o que se realiza entre a obra e seu público: a quem se destina; com quem estabelece interlocução; quais vínculos são construídos; que aspectos podem ser privilegiados, entre outros. Esse intervalo reforça o caráter inacabado que o texto/filme possui na medida em que cada leitor/espectador pode construir significados a partir de um aspecto em particular ou pode ainda olhar para a unidade da obra. Em todas as leituras o objetivo continua sendo o mesmo, isto é, mostrar como pessoas cegas se tornam protagonistas em um mundo construído para videntes. Por exemplo, Evilázio e Jailson concordam que lidar com as respectivas famílias foi a maior de suas dificuldades. Isto porque, embora as reações tenham sido diferentes, foi o comportamento deles que as fez entender que cegueira não pode ser sinônimo de isolamento social, aprendizado que o vídeo contribui para disseminar entre as pessoas. Por não ficarem confinados no ambiente familiar, eles puderam estudar, ter uma formação profissional e ajudar outras pessoas (incluindo videntes) a superarem as limitações que lhes são impostas. 
Outra leitura pode convergir para a atuação do Instituto de Cegos. Em atividade desde 1933, o Instituto é uma organização da sociedade civil sem fins lucrativos e atende pessoas já a partir do nascimento. Entre os serviços prestados encontram-se o de apoio terapêutico e o de intervenção precoce. No site oficial, há orientações pertinentes sobre como lidar com um deficiente visual, todas voltadas para reorientar a forma como os videntes percebem a deficiência, ou seja, é bastante comum percebemos a deficiência sempre pela falta ou perda de capacidade, a exemplo das famílias mencionadas no parágrafo anterior. Evilázio relata que precisava fugir de casa para ter acesso aos serviços básicos, pois sua família tinha medo de deixá-lo andar sozinho nas ruas. Intitulado "Como lidar com o deficiente visual", os conselhos auxiliam em várias circunstâncias, entre os quais um nos chama bastante atenção: "Fale diretamente para o deficiente visual, não à pessoa ao seu lado, perda de visão não é perda de intelecto". Claro indício de que as limitações existentes decorrem da postura adotada pelo vidente que lida com o deficiente visual.

No Instituto, Jailson aprendeu a conviver com a deficiência visual. Lá aprendeu a andar usando bengala, a fazer artesanatos (uma das primeiras atividades do órgão era ensinar os deficientes e suas famílias a construírem vassouras). Depois passou a frequentar a Associação de Cegos da Bahia onde fez os cursos de massoterapia e manutenção predial. A parceria com Evilázio veio depois que ele precisou de um material e o amigo lhe ofereceu o curso de manutenção de micro-ondas para que depois pudessem formar mais pessoas. $O$ projeto ainda está em fase inicial. A primeira turma foi montada em 2016 na Associação como forma de retribuir a ajuda recebida (Imagem 1).

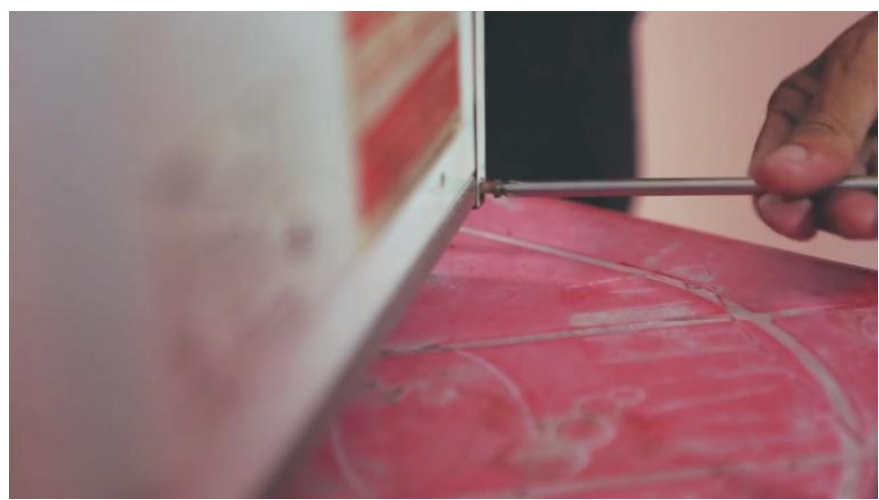

Close do aparelho de micro-ondas usado na oficina. 
Uma terceira leitura pode ser feita a partir do Residencial Bosque das Bromélias. No território, Jailson é uma liderança porque ele coloca suas necessidades ao lado de outras demandas da comunidade e orienta a todos a buscar melhorias. Dessa forma, o direito que ele tem de ter um piso tátil, por exemplo, assemelha-se ao direito que uma mãe tem de deixar seu filho pequeno na creche ou na escola enquanto trabalha. Não importa a natureza da necessidade; importa que as pessoas saibam como buscar solucioná-las, conforme ele destaca: "Eu quero que cada um tenha liberdade para brigar pelo que é de direito". A chegada do projeto ao empreendimento reforça o discurso de Jailson na medida em que contribui para o desenvolvimento sustentável do lugar, ao mesmo tempo em que ratifica a qualidade de sua liderança: ele participa da maioria dos cursos e oficinas ofertados; auxilia a equipe do projeto a ter acesso às famílias e implementar as ações necessárias; contribui para o bem estar de todos ao participar do planejamento estratégico das atividades; enfim, sabe como movimentar a cena em prol do bem comum.

Cada uma das instâncias mencionadas anteriormente - família, Instituto/Associação, residencial - tem um papel decisivo na formação de Jailson. A família por buscar orientações adequadas no momento em que percebe que ele não pretende acomodar-se no ambiente doméstico, conforme relata: "A adaptação... assim... pra mim, ela não foi tão difícil... porque... assim... talvez pra minha família foi mais difícil que pra mim. Eu já... já tinha noção das coisas” (sic).

O Instituto por ter proporcionado o desenvolvimento de habilidades necessárias para ele lidar com a deficiência visual:

Em agosto de 86 eu fui levado ao Instituto de Cegos da Bahia, através da minha família, aonde eu pude conhecer e aprender a conviver com minha deficiência visual. 87, no primeiro semestre eu já tava andando com bengala, onde eu tive aula de locomoção. Comecei a tomar minha primeira liberdade, meus primeiros passos. Lá também eu aprendi a trabalhar com artesanato. Fazia sacolas, tapetes, trabalhava com marcenaria. Então um monte de coisas, lá no Instituto eu aprendi através da minha deficiência (sic).

O Residencial tem sido importante ao oferecer um ambiente em que ele pode conviver com os vizinhos como igual. 
O que eu gostei... é... das Bromélias e gosto é da forma que a população me apoiou. Ela me apoiou de uma forma tão diferente das localidades que eu já passei. Igual lá, eu acho que não sei se vou conseguir uma oportunidade como eu consegui nas Bromélias. Então... assim... pra mim, as coisas lá é muito mais fácil (sic).

O apoio recebido fortalece a comunidade na medida em que a ajuda mútua se transforma em crescimento coletivo. Talvez por isso, ele tenha conseguido superar as dificuldades mais rapidamente no Bromélias do que em outros locais. Dificuldades que podem estar relacionadas tanto à sua deficiência quanto às enfrentadas por qualquer outro morador, como a mudança para um ambiente novo pode evidenciar.

Outra peculiaridade do vídeo é a constituição da mise en scène, entendida como o discurso que viabiliza a performance uma vez que cada elemento cênico concorre para a significação do produto:

[...] o discurso da performance é o discurso da mise en scène, tornando o performer uma parte e nunca o todo do espetáculo (mesmo que ele esteja sozinho em cena, a iluminação, o som etc. serão tão importantes quanto ele - ele poderá ser todo enquanto criador mas não enquanto atuante) (COHEN, 2002, p. 102).

Embora não seja um espetáculo teatral, Jailson assume uma postura altamente performática. Não por acaso, ele inicia a fala a partir do lugar de um contador de histórias. Sentado diante da câmera, ele brinca com a possibilidade de não seguir adiante e pergunta se a "plateia" quer que ele conte sua história: "Não sei se vocês querem que eu conte". Ouve-se em off a voz da equipe afirmando positivamente. Respira sério. Cria-se uma expectativa. Estaria ele melhorando a realidade para se fazer ouvir ou estava apenas se familiarizando com o suporte? "Pode?" é a pergunta final. Corta para a tela preta onde surge o nome do documentário ao som de uma música bastante otimista. Quando a tela volta a ficar completamente escura, sem nenhuma palavra, a voz em off de Jailson ecoa: "Eu fiquei cego...". Em seguida sua imagem surge pouco iluminada e vai clareando aos poucos. O depoimento é todo gravado de um mesmo ângulo, variando apenas o enquadramento, close ou primeiríssimo plano, por exemplo, (Imagem 2). 


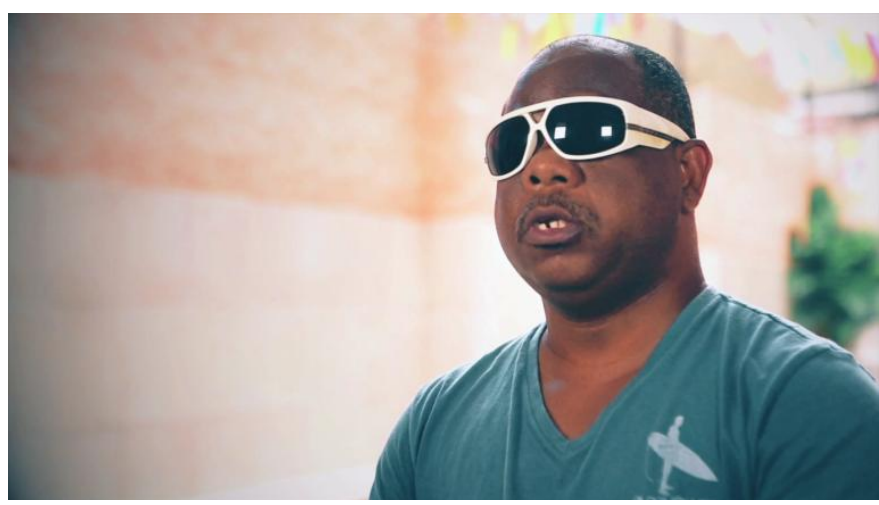

Posicionamento de Jailson durante o depoimento.

Além disso, ele não atua sozinho. O enquadramento aproxima os interlocutores, como se estivessem conversando lado a lado. Mas para causar a impressão de realidade pretendida, isto é, provar que seu discurso é verdadeiro, é preciso mostrar mais. Nesse sentido, o espectador é levado aos lugares frequentados por Jailson não apenas por suas palavras, mas também pelas imagens apresentadas: no Instituto, o vemos subindo as escadas do prédio com autonomia; em casa, ele faz a manutenção de uma tomada; depois, participa da oficina de conserto de micro-ondas; e no Residencial, temos uma visão panorâmica do empreendimento enquanto ele caminha como se estivesse indo a algum lugar ao mesmo tempo em que é abordado por vizinhos. Em alguns momentos, seguimos seus passos com a câmera baixa e constatamos que a acessibilidade ainda é precária: calçadas irregulares e mal conservadas.

O conceito de mise en scène é importante por compreender que a significação de um produto (peça teatral, performance, e aqui incluímos o documentário) é construída a partir da escolha, consciente ou não, de cada elemento cênico. No documentário Muito além da visão, entendido como um texto autoral - ao estilo de uma carta - centrado na figura de Jailson, que fala de si para vários destinatários e se coloca à disposição do olhar do outro, a realidade é articulada de modo a evidenciar a subjetividade do sujeito que fala, mas também constrói uma subjetividade coletiva, na medida em que, por não falar sozinho, cada pessoa com quem ele interage é igualmente responsável pela constituição de algo maior, em constante transformação.

Por esse motivo, a participação de Evilázio não pode ser vista como menor. Requisitado para contar sua versão dos fatos de modo a contrapor a fala de Jailson, 
ele também dá exemplos importantes de como a sociedade se organiza e de como ainda estamos distante de uma realidade mais inclusiva:

Eu nasci cego. Os meus pais... é... tinham dificuldade em me incluir nas atividades normais, nas atividades da casa. Os meus irmãos, eles iam pra roça trabalhar e nesse meio tempo que eles iam pra roça ficava mexendo em uma coisa, mexendo em outra, porque eu queria fazer algo. Eu achava sinceramente que ficar parado não era bom. Ficar parado não ia me fazer bem (sic).

Diferente do amigo, ele já nasceu cego e, quando narra detalhes de seu processo de inclusão, ainda entre os familiares, demonstra ter consciência de que a normalidade é um conceito imposto por aqueles que têm dificuldade em conviver com a diferença. Além disso, ao passo em que segue narrando, ensina que a inclusão é um desafio não apenas das pessoas com deficiência, mas principalmente daquelas que não a possui: "A mensagem que eu deixo é que sejamos pósconceituosos e não preconceituosos. Existe essa coisa da pessoa não acreditar e a gente querer provar que pode". Utilizamos o prefixo pós em várias circunstâncias, tais como pós-moderno, e o ignoramos quando se trata de aceitar o outro e suas especificidades.

Voltando a Eni Orlandi (2003) quando afirma que "a leitura é produzida", entendemos que o documentário é produzido desde a idealização do vídeo por Jailson que procura a equipe do Projeto para sugerir a matéria, se estende à manufatura - filmagens e edição - e culmina com a recepção pelos espectadores. Cada um, realizando leituras e interpretações de acordo perspectivas próprias. No entanto, o que o vídeo produz, acima de tudo, são formas específicas de resistência e enfrentamento da realidade.

\section{REFERÊNCIAS}

COHEN, Renato. Performance como linguagem: criação de um tempo espaço de experimentação. São Paulo: Perspectiva, 2002.

FOUCAUL, Michel. "A escrita de si”. In: FOUCAULT, Michel. Ditos e escritos: Ética, sexualidade, política. Trad. Elisa Monteiro; Inês Autran Dourado Barbosa. Rio de Janeiro: Forense Universitária, 2004. 
ORLANDI, Eni Puccinelli. "Uma questão da leitura: a noção de sujeito e a identidade do leitor". In: ORLANDI, Eni Puccinelli. A linguagem e seu funcionamento: as formas do discurso. 4 ed. Campinas, SP: Pontes, 2003. p.177-191.

http://www.institutodecegosdabahia.org.br/

https://labor.ufba.br/ 